\title{
Psycho sexual profile of perimenopausal and post-menopausal women visiting a tertiary care centre
}

\author{
Smita Sharma*, Poonam Mani, Shashi Prateek, Lalita Yadav, Jasneet Dhingra
}

Department of Obstetrics and Gynecology, N.S.C.B. Subharti Medical College, Meerut, Uttar Pradesh, India

Received: 09 August 2017

Revised: 04 September 2017

Accepted: 09 September 2017

\section{*Correspondence:}

Dr. Smita Sharma,

E-mail: docsmita1@gmail.com

Copyright: () the author(s), publisher and licensee Medip Academy. This is an open-access article distributed under the terms of the Creative Commons Attribution Non-Commercial License, which permits unrestricted non-commercial use, distribution, and reproduction in any medium, provided the original work is properly cited.

\begin{abstract}
Background: The objective was to study the psychosexual profile of perimenopausal and postmenopausal females visiting a tertiary care centre.

Methods: The present study was carried out in the Obstetrics and Gynecological Department of Subharti Medical College and Hospital from July 2013 to June 2015.A questionnaire was made including the questions regarding the various symptoms and problems encountered by both peri and postmenopausal females. A detailed interaction in the form of history and examination was done on a total of 220 patients which included both type of females. They were then given a questionnaire which they filled it by themselves or with assistance from our side. The females in both the groups were then analysed on the presence or absence of a particular symptom and whether the difference was statistically significant or not and the data was analysed using Chi square test.

Results: The study showed varied symptoms in both the type of females be it Perimenopausal or post-menopausal. The vasomotor and the psychological symptoms were more common in the perimenopausal females whereas the physical and sexual symptoms were more common in post-menopausal females. Variations from this pattern were also found. The mean age of menopause was found to be 48.3 years with only $1.81 \%$ females above 70 years.

Conclusions: The perimenopausal and postmenopausal females do undergo many physiological as well as psychological changes that surely affects their social, personal as well as sexual life. Thus they require a lot of care and support and adequate evaluation so that they can be treated well.
\end{abstract}

Keywords: Menopause, Menopausal transition, Perimenopause, Psychosexual profile

\section{INTRODUCTION}

The term Menopause is derived from Greek language where pausis means to stop and mens refers to menstrual cycle. The WHO defines menopause as the cessation of menses for a period of one year (natural menopause) or the surgical removal of the uterus along with or without ovaries (surgical menopause). ${ }^{1}$

In other words the time period after the "final menstrual period" or FMP is when a woman formally enters menopause. This definition although practical, overtly simplifies what is actually an abrupt, stormy and sometimes extremely debilitating transition that can transform a fertile, healthy, productive woman into a confused, emotionally labile woman beset with a variety of health issues and incapable of bearing children.

Menopause can be a dramatic event in a woman's life that is as important as childbirth and puberty. However, it is rarely accorded the same significance especially in Indian culture since it is considered a natural part of 
ageing and therefore not exactly a cause for concern or celeberation.

There have been several attempts to quantify the multiple menopausal symptoms in order to understand them and manage them in a better way. Several scales and tools were tried including Kupperman's index, Greene's climacteric scale and the Likert's scale. ${ }^{2,3}$ In 1996, the menopausal quality of life (MENQOL) was developed as a tool based on assessment of the common menopausal complaints ${ }^{4}$.

Numerous Western studies including SWAN (Study of women's health across the nation) was developed as a tool based on assessment of the common menopausal complaints. $^{4}$

There have been numerous western studies including SWAN (study of women's health across the nation); penn ovarian ageing study (POAS) and MEPI (menopausal epidemiology study) that have tried to assess the impact of menopause on a woman's health. ${ }^{5-7}$ In India, the data's relatively sparse and consists of only a few large population based studies. ${ }^{2,3}$

It is now recognized that in the phase of reproductive decline although women continue to menstruate, she nevertheless enters "perimenopause". Kriplani et al in their study in 2005 put the average age of menopause in India at about 46 years and this was confirmed once again in 2012 by Singh which looked at the age at natural menopause as a marker for preventive health programme. Unlike the age at menarche, the age at menopause has remained unchanged since antiquity. The years immediately following menopause are marked by several changes that are immediately apparent such as vasomotor, dermatological and sexual. Serious health issues are uncommon in this period which lasts for about 5 years after the final menopausal period. The final phase is late menopause which lasts till death and is marked by debilitating conditions like osteoporosis and occasionally malignancies. These changes however are also related to ageing itself and both are inextricably linked.

Aims and objectives of present study were to study the various symptoms of presentation pertaining to menopause and to assess the physical ailments attributed to menopause in these women.

\section{METHODS}

The present study was conducted in Subharti Medical College, Meerut from July 2013 to June 2015. This included both women with complaints as well as women who accompanied other patients with no obvious complaints. The inclusion criteria were all women who belonged to STRAW -2 to +2 .

The exclusion criteria were presence of any major gynaecological or medical problems.
A total of 220 patients were recruited for the study. A detailed verbal informed consent was obtained from all participants.

A questionnaire was then administered to all the participants, in order to quantify the menopausal symptoms and thereby provide benefits of therapeutic intervention. The study participants were entered in to two groups.

\section{- perimenopausal \\ - post-menopausal}

As majority was illiterate, their family members too cooperated in the study by explaining the questions to them. The patients who were symptomatic were managed accordingly and were also referred to orthopaedician for management of osteoporosis and other related complaints of backache and aches of muscles and joints.

The patients who had any psychological symptoms were given psychotherapy and were sent for psychiatric opinion as well. Isoflavone derivatives, topical estrogens, calcium supplementations, oral medications were given after screening for diabetes and hypertension or any history of heart disease.

\section{RESULTS}

The total participants was 220 with post-menopausal being 78 and perimenopausal 142. Out of the 78 postmenopausal females 19 patients had surgical menopause $(24.35 \%)$. The major cause of surgery was menstrual complaints $(8 / 19=42.1 \%)$ the other problems being UV Prolapse, uterine and adnexal pathologies including fibroid uterus, ovarian tumors etc. $33.18 \%$ were between 40 to 45 years and only $1.81 \%$ were above 70 yrs.

Table 1: Vasomotor symptoms.

\begin{tabular}{|llll|}
\hline $\begin{array}{l}\text { Presence } \\
\text { of } \\
\text { symptoms }\end{array}$ & $\begin{array}{l}\text { Perimenopausal } \\
\text { females }(\mathrm{n}=\end{array}$ & $\begin{array}{l}\text { Postmenopausal } \\
\text { females }(\mathbf{n}=78) \\
(\%)\end{array}$ & $\begin{array}{l}\mathbf{P} \\
\text { value }\end{array}$ \\
\hline $\begin{array}{l}\text { Hot } \\
\text { flushes }\end{array}$ & $95(66.9)$ & $20(25.64)$ & $<0.005$ \\
\hline Sweating & $110(77.46)$ & $17(21.79)$ & $<0.005$ \\
\hline $\begin{array}{l}\text { Night } \\
\text { sweats }\end{array}$ & $90(63.38)$ & $14(17.5)$ & $<0.005$ \\
\hline
\end{tabular}

$48.6 \%$ of the total patients were illiterate and $38.18 \%$ pursued some occupation. $42.27 \%$ patients had history of tubal ligation. Majority of the participants belonged to lower socioeconomic class $(41.36 \%)$.

The Table 1 shows that the vasomotor symptoms were more pronounced in perimenopausal females. Though often neglected these vasomotor symptoms were the most distressing complaints with which the patients reported to the OPD. These systems were often confused with 
psychological symptoms.The Table 2 suggests that psychological symptoms like feeling anxious, accomplishing less, feeling depressed and flatulence were found more in postmenopausal females and the difference was statistically significant and rest of the symptoms were more in perimenopausal females.

Table 2: Psychological symptoms.

\begin{tabular}{|llll|}
\hline Presence of symptoms & $\begin{array}{l}\text { Perimenopausal } \\
\text { females }(\mathbf{n = 1 4 2})(\%)\end{array}$ & $\begin{array}{l}\text { Postmenopausal } \\
\text { females }(\mathbf{n}=\mathbf{7 8})(\%)\end{array}$ & \begin{tabular}{l} 
P value \\
\hline Poor memory
\end{tabular} \\
\hline Dissatisfaction with personal life & $84(74.64)$ & $48(61.54)$ & 0.0419 \\
\hline Feeling anxious or nervous & $88(61.97)$ & $35(44.87)$ & 0.8026 \\
\hline Accomplishing less than what she did earlier & $31(21.83)$ & $47(60.26)$ & $<0.05$ \\
\hline Feeling depressed or down & $78(54.92)$ & $56(71.79)$ & $<0.05$ \\
\hline Being emotionally labile or impatient with others & $113(79.58)$ & $63(80.76)$ & $<0.05$ \\
\hline Flatulence or gas & $29(20.42)$ & $57(73.07)$ & 0.2710 \\
\hline
\end{tabular}

Table 3: Physical symptoms.

\begin{tabular}{|c|c|c|c|}
\hline Presence of symptoms & $\begin{array}{l}\text { Perimenopausal } \\
\text { females }(n=142)(\%)\end{array}$ & $\begin{array}{l}\text { Postmenopausal } \\
\text { females }(n=78)(\%)\end{array}$ & P value \\
\hline Feeling tired or worn out & $107(75.35)$ & $60(76.92)$ & $<0.05$ \\
\hline Aches in back of head or neck & $32(22.54)$ & $57(73.08)$ & $<0.05$ \\
\hline Decrease in stamina & $118(83.10)$ & $60(76.92)$ & 0.2648 \\
\hline Dry skin & $39(27.46)$ & $37(47.43)$ & $<0.05$ \\
\hline Increase in facial hair & $16(11.27)$ & $27(34.61)$ & $<0.05$ \\
\hline Feeling bloated & $47(33.10)$ & $28(35.89)$ & 0.6752 \\
\hline Frequent urination & $117(82.39)$ & $55(70.51)$ & $<0.05$ \\
\hline Decrease in sexual desire & $109(76.76)$ & $67(85.89)$ & $<0.0001$ \\
\hline Vaginal bleeding or spotting & $38(26.76)$ & $15(19.23)$ & 0.2781 \\
\hline Feeling of wanting to be alone & $112(78.87)$ & $59(75.64)$ & 0.7026 \\
\hline Aching of muscles and joints & $129(90.84)$ & $73(93.59)$ & 0.0042 \\
\hline Difficulty in sleeping & $88(61.97)$ & $47(60.26)$ & 0.9162 \\
\hline Decrease in physical strength & $126(88.73)$ & $59(75.64)$ & 0.0189 \\
\hline Lacking of energy & $130(91.54)$ & $59(75.64)$ & 0.0024 \\
\hline Weight gain & $81(57.04)$ & $17(21.79)$ & 0.0001 \\
\hline
\end{tabular}

Table 4: Sexual symptoms.

\begin{tabular}{|llll|}
\hline Presence of symptoms & $\begin{array}{l}\text { Perimenopausal } \\
\text { females }(\mathbf{n = 1 4 2})(\%)\end{array}$ & $\begin{array}{l}\text { Postmenopausal females } \\
(\mathbf{n = 7 8})(\%)\end{array}$ & $\begin{array}{l}\text { P value } \\
\text { Changes in appearance, texture, tone of skin }\end{array}$ \\
\hline $119(83.80)$ & $48(61.54)$ & 0.0004 \\
\hline Involuntary urination while coughing and sneezing & $37(26.06)$ & $28(35.89)$ & 0.1688 \\
\hline Vaginal dryness & $105(73.94)$ & $42(53.84)$ & 0.0029 \\
\hline Breast pain or tenderness & $103(72.53)$ & $19(24.36)$ & $<0.0001$ \\
\hline
\end{tabular}

Physical symptoms mentioned in Table 3 like decrease in stamina, dry skin, decrease in sexual desires, aches of muscles and joints were found more in postmenopausal females and the difference was statistically significant whereas symptoms like frequent urination, lack of energy and weight gain were more common in perimenopausal females, the result again being statistically significant.

Rest of the symptoms were variably found in both the groups and the results were statistically insignificant. 
Table 5: Others.

\begin{tabular}{|llll|}
\hline Presence of symptoms & $\begin{array}{l}\text { Perimenopausal } \\
\text { females }(\mathbf{n = 1 4 2})(\%)\end{array}$ & $\begin{array}{l}\text { Postmenopausal } \\
\text { females }(\mathbf{n = 7 8})(\%)\end{array}$ & \begin{tabular}{l} 
P value \\
\hline Uterus considered as vestigial after menopause
\end{tabular} \\
\hline Decrease in vision due to menopause & $17(11.97)$ & $41(52.56)$ & 0.253 \\
\hline Ever taken HRT & $64(45.07)$ & $41(52.56)$ & 0.0001 \\
\hline Awareness about disappearence of reproductive functions & $129(90.84)$ & $33(42.30)$ & 0.7765 \\
\hline Ever consulted any psychiatrist & $10(7.04)$ & $45(57.69)$ & $<0.0001$ \\
\hline Vaginal atrophy & $7(4.92)$ & $22(28.20)$ & 0.7746 \\
\hline
\end{tabular}

Sexual symptoms like Change in appearance, vaginal dryness and breast pain were found more in perimenopausal females whereas the others were found more in postmenopausal females and the results were statistically significant as seen by the $\mathrm{p}$ value as stated in Table 4.

The symptom of vaginal atrophy was found more in postmenopausal females and the difference being statistically significant. The disappearance of reproductive functions was found in both but the awareness was more in perimenopausal females as mentioned in Table 5.

\section{DISCUSSION}

Menopausal health requires a lot of attention. Most women in India too lie in the perimenopausal and postmenopausal category. A lot of studies have been conducted and are ongoing in order to analyse, evaluate and discuss the issues and problems faced by these women and the feasible solutions available to curb them.

The mean age at menopause in our study was found to be 48.3. Most Indian studies show wide variations in the age at menopause probably due to differences in socioeconomic status and nutritional levels.

The comparable study among urban women from Karnataka by Bairy et al had a mean age at menopause of about 48.7 years. $^{8}$ In SWAN, $60-80 \%$ of females experienced vasomotor symptoms at some point during the menopausal transition, with prevalence rate varying by racial/ethnic group, the rates being higher among African Americans. ${ }^{5}$ The duration of perimenopause varies widely and can range between 2-7 years and inevitably ends in menopause or the cessation of menstrual cycles. McKinlay et al in their study found that the average age at menopause is about 50 years. ${ }^{9}$ Indian women in general seem to attain menopause at an earlier age, the average age being about 46 years.

The vasomotor symptoms like hot flushes, sweating and night sweats were more common in perimenopausal females and the results were statistically significant with $\mathrm{p}<0.05$ whereas according to Kapur et al these symptoms were found more in postmenopausal females. ${ }^{10}$ According to Marahatta in 2012, vasomotor symptoms were found more in perimenopausal females as compared to postmenopausal females. ${ }^{11}$

The psychological symptoms like feeling anxious or nervous, accomplishing less, feeling depressed and flatulence were more common in perimenopausal females, the results being statistically significant. The rest of these symptoms did not show any variations in peri and postmenopausal females.

Hay et al investigated 78 peri/postmenopausal females and noted that $45 \%$ were depressed more so in perimenopausal females. ${ }^{12}$ One study by Ballinger also concluded that Depressive symptoms were more frequent in perimenopausal females. ${ }^{13}$ Also The Massachusetts Women's Health Study indicated that a long period of perimenopause was also associated with depression. ${ }^{14}$

It is known that the menopause has a transient yet distinct effect on cognition. This impairment in cognition is also negatively influenced by both vasomotor as well as mood changes. These changes most commonly involve verbal memory and learning and have their onset at the beginning of Menopausal Transition and resolve after menopause.

Brann et al studied the neurotropic and neuroprotective actions of estrogens and it has been found that estrogens have a beneficial effect on cognition.

The physical symptoms like feeling tired, decrease in stamina, feeling bloated, vaginal bleeding or spotting, loneliness and difficulty in sleeping were found more in perimenopausal females but the result was statistically insignificant whereas symptoms like aches in back of head and neck, dry skin, increased facial hair, frequent urination, decreased sexual desire, aching of muscles and joints, decreased physical strength, lack of energy and weight gain were found more in postmenopausal females and the result was statistically significant. Studies like SWAN and POAS suggested that a large number of women both peri and post-menopausal experience somatic symptoms but were found more in postmenopausal females.

Sexual symptoms were found equally in peri and postmenopausal females. Studies like those of Williams et al found these symptoms more in post-menopausal 
females, the reason of this difference being small sample size. $^{7}$ The other symptoms were observed as well. Symptoms like vaginal dryness, urinary symptoms, changes in skin tone and texture etc. were found more in postmenopausal females as stated by Mislom et al. ${ }^{15}$

\section{CONCLUSION}

220 patients were recruited for the study from Subharti Medical College Meerut outpatient department, 78 were menopausal and 142 perimenopausal. A questionnaire was formulated and was administered to all the participants after obtaining verbal informed consent and their responses were recorded on a proforma. The responses were analysed using Chi Square test. The mean age of menopause was 48.3 years.

The vasomotor and psychological symptoms were found more in perimenopausal females and the physical and sexual symptoms were found more in postmenopausal females. Women in our study accepted menopause as a natural transition in life. Despite the fairly high prevalence of some menopausal symptoms especially somatic and psychological symptoms, most women neither requested nor accepted any medications for the same.

Most women in our study still lived with their children and grandchildren in an elaborate and complicated joint family set up. The financial implications of such a setup also contributed in large measure to their health in general and menopausal health in particular should involve the women and their family members.

Funding: No funding sources

Conflict of interest: None declared

Ethical approval: The study was approved by the Institutional Ethics Committee

\section{REFERENCES}

1. World Health Organisation (WHO). Report of WHO scientific group on the menopause in the 1990s.1996. WHO technical report series 866. Geneva: WHO.

2. Shah D, Agarwal S. Vasomotor symptoms: Viewpoint from the Indian subcontinent and management of a common menopausal problem. Semin Reprod Med. 2010;28(5):388-95.

3. Kapur P, Sniha B, Pereira BM. Measuring Climacteric symptoms and age at natural menopause in an Indian population using the Greene Climacteric Scale. Menopause. 2009;16(2):378-84.
4. Hilditch JR, Lewis J, Peter A, van Maris B, Ross A, Franssen E, et al. A menopause specific quality of life questionnaire: development and psychometric properties. Maturitas. 1996;24(3):161-75.

5. Janssen I, Powell LH, Crawford S, Lasley B, SuttonTyrrell K. Menopause and the metabolic syndrome: the study of women's health across the Nation. Arch Intern Med. 2008;168:1568-75.

6. Freeman EW, Sammel MD, Lin H, Gracia CR, Pien GW, Nelson DB, et al. Symptoms associated with menopause transition and reproductive hormones in midlife women. Obstet Gynecol. 2007;110(2 Pt 1):230-40.

7. Williams RE, Levine KB, Kalilani L, Lewis J, Clark RV. Menopause specific questionnaire assessment in US population based study shows negative impact on health quality of life.Maturitas. 2009;62(2):153-9.

8. Bairy L, Adiga S, Bhat P, Bhat R. Prevalence of menopausal symptoms and quality of life after menopause in women from South India. Aust N Z J Obstet Gynaecol. 2009;49(1):106-9.

9. McKinlay SM, Brambilla DJ, Posner JG. The normal menopause transition. Maturitas. 1992;14:103-15.

10. Kapur P, Sinha B, Pereira BM. Measuring Climacteric symptoms and age at natural menopause in an Indian population using Greene Climacteric Scale. Menopause. 2009; 16(2):378-84.

11. Dr Rita Marahatta (Khanal); Study of symptoms among peri and postmenopausal women attending NMCTH. Nepal Med Col J. 2012;14(3):251-5.

12. Hay AG, Bancroft J, Johnstone EC. Affective Symptoms in Women attending a Menopause clinic. Br J Psychiatry. 1994;164:513-6.

13. Ballinger et al. Hormone profiles and psychological symtoms in peri-menopausal women. 1987;9(3):23551.

14. Massachusetts Women Health Study: an epidemiologic investigation of the menopause. J Am Med Women's Associat. 1972;50(2):45-9.

15. Mislon I, Arvidsson L, Ekelund P, Molander U, Eriksson O. Factors influencing vaginal cytology, $\mathrm{Ph}$ and bacterial flora in elderly women. Acta Obstetrica Gynaecologica Scandinavica. 1993;72:286-91.

Cite this article as: Sharma S, Mani P, Prateek S, Yadav L, Dhingra J. Psycho sexual profile of perimenopausal and post-menopausal women visiting a tertiary care centre. Int J Reprod Contracept Obstet Gynecol 2017;6:4613-7. 